\title{
BMJ Open Impact of educational level and employment status on short-term and long-term pain relief from supervised exercise therapy and education: an observational study of 22588 patients with knee and hip osteoarthritis
}

\author{
Marianne Bakke Johnsen (D) , ${ }^{1,2}$ Ewa Roos (D) , ${ }^{3}$ Dorte Thalund Grønne (D) , \\ Lars Christian Haugli Bråten, ${ }^{1,2}$ Søren Thorgaard Skou (i) ${ }^{3,4}$
}

To cite: Johnsen MB, Roos E, Grønne DT, et al. Impact of educational level and employment status on shortterm and long-term pain relief from supervised exercise therapy and education: an observational study of 22588 patients with knee and hip osteoarthritis. BMJ Open 2021;11:e045156. doi:10.1136/ bmjopen-2020-045156

- Prepublication history and additional supplemental material for this paper are available online. To view these files, please visit the journal online (http://dx.doi.org/10.1136/ bmjopen-2020-045156).

Received 23 September 2020 Revised 19 March 2021 Accepted 23 March 2021
Check for updates

(c) Author(s) (or their employer(s)) 2021. Re-use permitted under CC BY-NC. No commercial re-use. See rights and permissions. Published by BMJ.

For numbered affiliations see end of article.

Correspondence to Dr Marianne Bakke Johnsen; m.b.johnsen@medisin.uio.no

\section{ABSTRACT}

Objectives To investigate the impact of educational level and employment status on change in pain intensity after treatment among patients with knee and hip osteoarthritis (OA).

Design A prospective cohort study.

Setting and participants We analysed 22588 patients participating in the Good Life with osteoArthritis in Denmark (GLA:D). GLA:D consists of two patient education sessions and 12 supervised exercise sessions.

Primary outcome Baseline educational level and employment status were used as exposures. We investigated the impact of both exposures separately on mean change in pain intensity (visual analogue scale 0-100 $\mathrm{mm}$ ) from baseline to immediately after treatment (approximately 3 months) and at 12 months, using linear mixed models.

Results On average, all patients improved in pain intensity. The average improvement in pain did not differ by educational level, except for one group. Patients with long-term education had less improvement after treatment $(2.0 \mathrm{~mm}, 95 \% \mathrm{Cl} 0.8$ to 3.1$)$ and at 12 months $(2.0 \mathrm{~mm}$, $95 \% \mathrm{Cl} 0.6$ to 3.4 ) compared with primary school only (reference). According to employment status, patients on sick leave had the greatest improvement in pain after treatment $(-3.4,95 \% \mathrm{Cl}-4.9$ to -1.9$)$ and at 12 months $(-4.5,95 \% \mathrm{Cl}-6.4$ to -2.6$)$ compared with retired patients (reference).

Conclusions On average, all patients reported improvement in pain at short-term and long-term followup. Change in pain intensity did not substantially differ by educational level or employment status, as the absolute differences were small and most likely not clinically important.

\section{INTRODUCTION}

A gradient of health exists for osteoarthritis (OA), with significant socioeconomic differences in the prevalence of knee OA, knee pain and health-related quality of life in

\section{Strengths and limitations of this study}

Data are based on a large number of patients with knee and hip osteoarthritis across Denmark who received treatment participating in the Good Life with osteoArthritis in Denmark programme.

- Measures of education, employment and pain intensity were self-reported.

- We had no data on income to better assess the individual's economic status included in the socioeconomic term.

- Results from the study may not be directly generalised to other countries/settings with different social structures.

favour of individuals with higher socioeconomic status (SES). ${ }^{1-3}$ Higher educational attainment, a frequently used proxy for individual-level SES, ${ }^{34}$ has also been associated with lower pain levels, better function and lower pain catastrophising measured prior to total knee replacement. ${ }^{4}$ In addition to disparities in health itself, inequities in healthcare utilisation is also associated with SES, ${ }^{5-8}$ as demonstrated by socioeconomic inequities in access to and outcomes after total joint replacement. ${ }^{5}$ Clinical guidelines for the management of knee and hip OA recommend exercise therapy, education and weight loss (when needed) as first line treatment, ${ }^{9}$ but little is known about whether SES is associated with the outcome of these treatments, although this would be important information in order to address any socioeconomic inequities by individualising care. The Good Life with osteoArthritis in Denmark (GLA:D) is an example of implementation of such guidelines in clinical practice. ${ }^{10}$ GLA:D 
consists of two patient education sessions followed by 12 sessions of $60 \mathrm{~min}$ supervised neuromuscular exercise (twice a week over 6 weeks) supervised by certified physiotherapists. The programme in GLA:D has previously shown to have a beneficial effect on short-term and longterm pain relief in patients with knee and hip OA. ${ }^{10}$ In the current study, we aimed to investigate the impact of educational level and employment status (as measures of SES) on change in pain intensity after supervised exercise therapy and education in patients with knee and hip OA participating in GLA:D. We hypothesised that lower SES (eg, primary school only or being on sick leave) would be associated with less improvement in self-reported pain immediately after the treatment programme (approximately 3 months after baseline) and at 12 months.

\section{METHOD}

\section{Design and the GLA:D programme}

We used registry-based data from the GLA:D programme ${ }^{10}$ to prospectively investigate the impact of SES on change in pain intensity. GLA:D is an ongoing nationwide initiative, initiated in January 2013, where the main aim is to implement and ensure that patients with knee and hip OA in Denmark are offered education and exercise, according to the clinical guidelines, prior to surgical referral. ${ }^{10}$ The programme includes two patient education sessions and 12 sessions of neuromuscular exercise (twice a week of 60 min each for 6 weeks), supervised by a GLA:D certified physiotherapist. The patient education focuses on information of OA, self-efficacy and treatment of OA, especially the importance of exercise. ${ }^{10}$ The exercise programme focuses on improving joint stability and neuromuscular control and is delivered in groups of 6-12 patients. The exercise programme has proven to be feasible and effective in different populations with knee or hip pain. ${ }^{11-13}$ Outcomes of self-reported pain, function and quality of life, among others, are evaluated immediately after the treatment (approximately 3 months after baseline) and at 12 months follow-up. A full description of the GLA:D programme is given elsewhere. ${ }^{10}{ }^{11}$ In the current study, we had access to data collected between January 2013 and end of May 2019. To ensure appropriate capture of 3 and 12 months follow-up data, we limited inclusion to participants with baseline assessment that occurred prior to 30 April 2018 ( $\mathrm{n}=28527)$. Patients with age less than 33 years or older than 91 years at baseline were truncated in the dataset to ensure anonymity of the data (figure 1). The local ethics committee of the North Denmark Region waived the need for an ethical approval of GLA:D. The GLA:D registry has been approved by the Danish Data Protection Agency, and all patients included have consented to submitting their data to the GLA:D registry, including that the data could be used for research purposes.

The current study conforms with the recommendation of Strengthening the Reporting of Observational Studies in Epidemiology. ${ }^{14}$

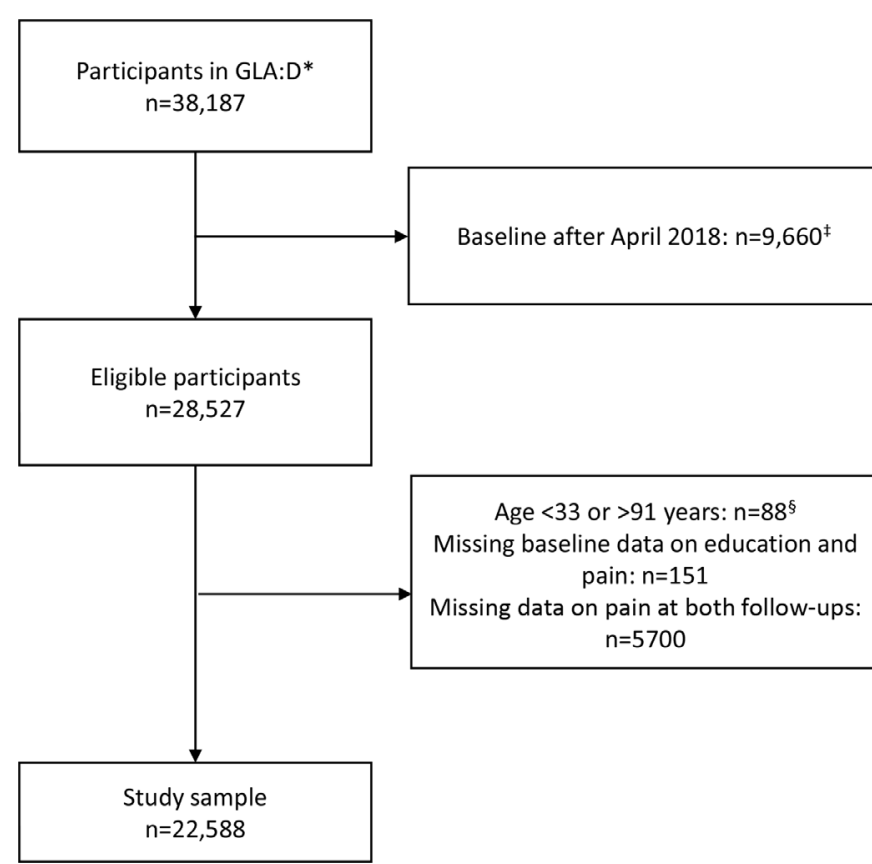

Figure 1 Flow chart of the study population. *Participants by 31 May 2019. ${ }^{\ddagger}$ Patients with baseline after 301 April 2018 were excluded due to insufficient time to undergo treatment and contribute with data at both follow-up time points.

§Patients who were missing chronological age were excluded from the current analysis. Age $<33$ or $>91$ years were truncated in the dataset to keep the anonymity of the data. GLA:D, The Good Life with osteoArthritis in Denmark.

\section{Study participants}

Patients with knee and/or hip joint pain or functional impairments associated with OA that resulted in contact with the healthcare system are eligible for the GLA:D programme. Patients are referred to the programme either by their general practitioner, by an orthopaedic surgeon or they can refer themselves directly to a GLA:D physiotherapist running the programme. Exclusion criteria include other reason for the joint complaints than $\mathrm{OA}$, for example, inflammatory joint and other symptoms that were more pronounced than the OA symptoms, for example, fibromyalgia. We included 22588 participants with knee and/or hip with available baseline data on educational level (main analysis) and pain intensity and data from at least one of the two follow-ups on pain intensity (figure 1).

\section{Outcome measures}

Change in self-reported average pain intensity during the last month in the most affected knee or hip was reported at baseline, immediately after the treatment and at 12 months. Pain intensity was evaluated on a visual analogue scale (VAS) ranging from 0 'no pain' to 100 'maximum pain'. A difference of minimum 15 points $/ \mathrm{mm}$ on the VAS pain score was considered clinically important, based on change in patients with chronic musculoskeletal pain (including OA). ${ }^{15}$ 


\section{Exposures}

Educational level was used as the main exposure and assessed by self-report in response to the question: 'What is the highest educational level you have completed?' and included the categories of: (1) primary school, (2) secondary school, (3) short-term education $(<3$ years after secondary school), (4) middle-term education (3-4 years after secondary school) and (5) long-term education ( $\geq 5$ years after secondary school).

Employment status was used as a secondary exposure and self-reported in response to the question, 'What is your current employment?' including the response alternatives employed/student, full-time sick leave, part-time sick leave, retired, unemployed, self-imposed early retirement and early retirement due to low ability to work. These seven alternatives were combined into five categories based on assumed economic status and for analytical purpose: (1) retired or self-imposed early retirement, (2) employed/student, (3) unemployed, (4) on sick leave part/full time and (5) early retirement due to low ability to work.

\section{Covariates}

Age, gender, the 12-Item Short Form Survey for mental component summary score (SF-12 MCS), number of comorbidities (patient reported (yes/no) to 12 conditions, for example, cardiovascular disease, diabetes and neurological disorders), body mass index (BMI) and prior surgery in most bothersome knee or hip joint (both registered by the physiotherapist prior to treatment) and self-reported physical activity (the University of California, Los Angeles) activity scale, 1-10, low to very high) were included as potential confounders.

\section{Statistical analysis}

We investigated the impact of education (main analysis) and employment status (secondary analysis) on change in pain intensity (VAS $0-100 \mathrm{~mm}$ ) from baseline to immediately after treatment, and between baseline and 12 months, using separate linear mixed models for each of the two exposures. Interaction with time (baseline, immediately after treatment and at 12 months) and education or employment were fixed effects. We performed both unadjusted and adjusted analyses. The adjustments for the two exposures differed slightly. For example, educational level was attained long time before baseline. According to the temporal assumption, some of the variables measured at baseline were therefore not considered to be confounders in the relationship between educational level and pain intensity, in contrast to the relationship between current employment status and pain intensity. ${ }^{16}$ In the model with education, we adjusted for age (continuous) and gender (male/female). In the model with employment, we additionally adjusted for BMI (continuous), educational level (categorical), SF-12 MCS (continuous), number of comorbidities (discrete) and prior surgery (no/yes). Direct acyclic graphs of the assumed relationships between variables in each of the models are available in online supplemental figures 1 and 2. We tested three different linear mixed models (random intercept for both clinic and patient level, random intercept and random slope or random intercept and unstructured covariance structure) and selected the model with the best fit based on the Akaike information criteria. Hence, we used a three-level design with patients nested in clinics with a random intercept at the clinic level and an unstructured covariance structure for the patient level residuals. The primary analysis was conducted for patients with knee and hip OA combined. In a sensitivity analysis, we stratified on the most affected OA joint site (knee/hip), based on the patients' reporting at the baseline examination with the physiotherapist. P values $<0.05$ were considered statistically significant. All analyses were performed in Stata V.16.1 (StataCorp, College Station, Texas, USA).

\section{Patient and public involvement statement}

No patients or public partners were involved in the design, conduct, interpretation and/or translation of the research in the current study.

\section{RESULTS}

In total 22588 patients with symptoms from knee or hip were included in the analysis (table 1 ). The most affected OA joint was the knee (74\%). In total, 19422 patients $(86 \%)$ reported to have a previous X-ray of their knee or hip, and $17784(92 \%)$ of these patients reported radiographically confirmed knee or hip OA. The majority of the patients were retired. The general retirement age in Denmark is currently 66 years. We observed a significant difference in the use of pain medication between educational levels $(p<0.001)$, with the primary school group reporting to use pain medication more often $(67 \%)$ than patients with long-term education (55\%). Patients excluded due to missing pain intensity at both at 3 and 12 months were similar to the study sample regarding mean age (64.4 years), BMI $\left(28.8 \mathrm{~kg} / \mathrm{m}^{2}\right)$ and the distribution of gender, use of pain medication, prior surgery and most affected joint, with the exception of slightly higher baseline pain ( $50.8 \mathrm{~mm}$ vs $47.4 \mathrm{~mm}$ ).

The unadjusted analyses are presented in online supplemental table 1 . In the adjusted analyses, patients with longer education reported in general lower mean pain intensity at baseline (table 2). The differences in mean pain intensity between patients with long-term education and patients with primary school only (reference) were from $-10.3 \mathrm{~mm}(95 \% \mathrm{CI}-11.4$ to -9.2$)$ at baseline to $-8.3 \mathrm{~mm}(95 \% \mathrm{CI}-9.6$ to -7.0$)$ at 12 -month follow-up. All educational groups improved in mean pain intensity over time (figure 2). There was an average improvement in pain intensity from baseline to immediately after treatment of $12.1 \mathrm{~mm}$ (95\% CI 11.4 to 12.9 ) and by $13.6 \mathrm{~mm}$ (95\% CI 12.7 to 14.6 ) at 12 months in the reference group (table 2). The average improvement for the educational groups did not statistically significantly differ from the 
Table 1 Baseline characteristics

\begin{tabular}{|c|c|c|c|c|c|c|}
\hline & \multicolumn{6}{|c|}{ Educational level } \\
\hline & $\begin{array}{l}\text { All indivduals } \\
\mathrm{n}=\mathbf{2 2 5 8 8}\end{array}$ & $\begin{array}{l}\text { Primary } \\
\text { school } \\
n=3846\end{array}$ & $\begin{array}{l}\text { Secondary } \\
\text { school } \\
\mathrm{n}=\mathbf{2 4 7 2}\end{array}$ & $\begin{array}{l}\text { Short-term } \\
\text { education* } \\
\mathrm{n}=\mathbf{4 4 7 5}\end{array}$ & $\begin{array}{l}\text { Middle-term } \\
\text { education† } \\
\mathrm{n}=\mathbf{9 1 8 3}\end{array}$ & $\begin{array}{l}\text { Long-term } \\
\text { education } \\
\mathrm{n}=\mathbf{2 6 1 2}\end{array}$ \\
\hline Age (years), mean (SD) & $65.0(9.3)$ & $68.1(8.5)$ & $64.4(10.1)$ & $63.3(9.5)$ & $64.5(8.9)$ & $65.3(9.1)$ \\
\hline $\mathrm{BMI}\left(\mathrm{kg} / \mathrm{m}^{2}\right)$, mean (SD) & $28.2(5.2)$ & $29.0(5.2)$ & $28.5(5.1)$ & $28.8(5.5)$ & $27.8(5.0)$ & $27.0(4.8)$ \\
\hline Female gender, $\mathrm{n}(\%)$ & $16374(72)$ & $2641(69)$ & $1606(65)$ & 3652 (82) & $6898(75)$ & $1577(60)$ \\
\hline \multicolumn{7}{|l|}{ Most affected OA joint, $n(\%)$} \\
\hline Knee & $16815(74)$ & $2854(74)$ & $1856(75)$ & $3378(75)$ & $6804(74)$ & $1923(74)$ \\
\hline Hip & $5772(26)$ & $992(26)$ & $616(25)$ & $1097(25)$ & $2378(26)$ & $689(26)$ \\
\hline Current smoking, $\mathrm{n}(\%)$ & $1801(8)$ & $364(10)$ & $218(9)$ & $426(10)$ & $656(7)$ & $137(5)$ \\
\hline \multicolumn{7}{|l|}{ Employment status, $\mathrm{n}(\%)$} \\
\hline Retired/self-imposed retirement & $13672(61)$ & $2813(73)$ & $1449(59)$ & $2399(54)$ & $5495(60)$ & $1516(58)$ \\
\hline Employed/student & $6804(30)$ & $593(15)$ & $740(30)$ & $1541(34)$ & 2960 (32) & $9707)$ \\
\hline Unemployed & $430(2)$ & $87(2)$ & $66(3)$ & $104(2)$ & $142(2)$ & $31(1)$ \\
\hline Sick leave (part/full) & $1009(4)$ & $196(5)$ & $144(6)$ & $249(6)$ & $370(4)$ & $50(2)$ \\
\hline Early retirement due to low work ability & $668(3)$ & $157(4)$ & $72(3)$ & $180(4)$ & $215(2)$ & $44(2)$ \\
\hline UCLA activity score (1-10)§, mean (SD) & $5.8(1.8)$ & $5.4(1.8)$ & $5.7(1.8)$ & $5.7(1.8)$ & $5.9(1.8)$ & $6.2(1.8)$ \\
\hline SF-12 MCS (0-100)ף, mean (SD) & $52.7(9.4)$ & $51.4(9.7)$ & $52.3(9.7)$ & $52.4(9.6)$ & $53.2(9.2)$ & $54.1(8.9)$ \\
\hline Pain intensity (0-100), mean (SD) & $47.4(21.8)$ & $51.9(21.7)$ & $49.3(21.7)$ & $48.4(21.7)$ & $46.1(21.3)$ & $41.3(21.6)$ \\
\hline \multicolumn{7}{|l|}{ Number of comorbidities ${ }^{* \star}, \mathrm{n}(\%)$} \\
\hline 0 & $9541(42)$ & $1345(35)$ & $1053(43)$ & $1893(42)$ & $4072(44)$ & $1178(45)$ \\
\hline 1 & $7656(34)$ & $1359(35)$ & $832(34)$ & $1494(33)$ & $3106(34)$ & $865(33)$ \\
\hline 2 & $3671(16)$ & $719(19)$ & $419(17)$ & $749(17)$ & $1384(15)$ & $400(15)$ \\
\hline$\geq 3$ & $1720(8)$ & $423(11)$ & $168(7)$ & 339 (8) & $621(7)$ & $169(6)$ \\
\hline Prior surgery††, n (\%) & $5036(22)$ & $729(19)$ & $563(23)$ & $1019(23)$ & $2174(24)$ & $551(21)$ \\
\hline Use of pain medication $\ddagger \neq, n(\%)$ & $14133(63)$ & $2592(67)$ & $1555(63)$ & $2925(65)$ & $5635(61)$ & $1429(55)$ \\
\hline Self-reported radiographic OA§§ & $17784(79)$ & $3079(80)$ & $1948(79)$ & $3536(79)$ & $7166(78)$ & $2055(79)$ \\
\hline \multicolumn{7}{|l|}{ Number of exercise therapy sessions, $n(\%)$} \\
\hline$>12$ & $6971(39)$ & $1225(39)$ & $732(37)$ & $1370(39)$ & $2835(40)$ & $809(42)$ \\
\hline $10-12$ & $7689(44)$ & $1455(47)$ & $908(46)$ & $1575(45)$ & $3042(43)$ & $709(37)$ \\
\hline $7-9$ & $1684(10)$ & $253(8)$ & $182(9)$ & $327(9)$ & $725(10)$ & $197(10)$ \\
\hline $1-6$ & $760(4)$ & $103(3)$ & $95(5)$ & $148(4)$ & $303(4)$ & $11(6)$ \\
\hline Did not attend & $548(3)$ & $77(2)$ & $55(3)$ & $99(3)$ & $227(3)$ & $90(5)$ \\
\hline \multicolumn{7}{|l|}{ Attendance patient education, $\mathrm{n}(\%)$} \\
\hline Theory session 1 & $15583(88)$ & $2782(89)$ & $1755(89)$ & $3113(88)$ & $6288(88)$ & $1645(86)$ \\
\hline Theory session 2 & $14992(85)$ & $2699(87)$ & $1682(86)$ & $3007(85)$ & $6045(85)$ & $1559(81)$ \\
\hline
\end{tabular}

Missing, if $n \geq 5$ : BMI: $n=55$, employment status; $n=5$, current smoking: $n=343$, UCLA score: $n=18, S F-12$ MCS: $n=55$ and attendance exercise and education sessions: $\mathrm{n}=4936$.

*Under 3 years after secondary school.

†3-4 years after secondary school.

$\ddagger$ At least 5 years after secondary school.

$\S$ Level 1 represents very low activity level, while level 10 is very high.

१Higher score indicates better mental health.

${ }_{\star *}$ Hypertension, cardiovascular disease, diabetes, lung disease, stomach disease, kidney or liver disease, blood disease, cancer, depression, rheumatoid arthritis, neurological disorders and other medical diseases.

††Prior surgery on the index joint registered by the physiotherapist before treatment.

¥¥At least one of the following medications: paracetamol, non-steroidal anti-inflammatory drug (oral or topical), morphine or other opioids.

$\S \S B$ Based on patients with a previous $X$-ray of the most affected joint and where $\mathrm{X}$-ray had shown OA.

BMI, body mass index; OA, osteoarthritis; SF-12 MCS, 12-Item Short Form Survey for mental component summary score; UCLA,

University of California, Los Angeles. 
Table 2 Knee and hip pain intensity at baseline and changes after 3 and 12 months following supervised exercise therapy and education

\begin{tabular}{|c|c|c|c|c|c|}
\hline & Pain intensity to & Pain intensity $t 3$ & & Pain intensity t12 & \\
\hline $\begin{array}{l}\text { Adjusted model } \\
\text { for education* }\end{array}$ & Mean $(95 \% \mathrm{Cl})$ & Mean $(95 \% \mathrm{Cl})$ & $\begin{array}{l}\text { Mean difference t0 } \\
\text { to t3 }(95 \% \mathrm{Cl})\end{array}$ & Mean (95\% Cl) & $\begin{array}{l}\text { Mean difference to } \\
\text { to t12 }(95 \% \mathrm{Cl})\end{array}$ \\
\hline $\begin{array}{l}\text { Primary school } \\
\text { (ref.) }\end{array}$ & $\begin{array}{l}\text { Mean difference } \\
(95 \% \mathrm{Cl})\end{array}$ & $\begin{array}{l}\text { Mean difference } \\
(95 \% \mathrm{Cl})\end{array}$ & $\begin{array}{l}\text { Difference in } \\
\text { change from to to t3 } \\
(95 \% \mathrm{Cl}) \text { in relation } \\
\text { to the ref. }\end{array}$ & $\begin{array}{l}\text { Mean difference } \\
(95 \% \mathrm{Cl})\end{array}$ & $\begin{array}{l}\text { Difference in } \\
\text { change from t0 } \\
\text { to } 112(95 \% \mathrm{Cl}) \text { in } \\
\text { relation to the ref. }\end{array}$ \\
\hline $\begin{array}{l}\text { Secondary } \\
\text { school }\end{array}$ & $-2.7(-3.8$ to -1.6$)$ & $-3.8(-4.9$ to -2.7$)$ & $-1.1(-2.3$ to 0.1$)$ & $-3.0(-4.4$ to -1.6$)$ & $-0.3(-1.8$ to 1.2$)$ \\
\hline $\begin{array}{l}\text { Short-term } \\
\text { education } †\end{array}$ & $-4.2(-5.2$ to -3.3$)$ & $-4.9(-5.9$ to -4.0$)$ & $-0.7(-1.7$ to 0.3$)$ & $-3.4(-4.6$ to -2.3$)$ & $0.8(-0.5$ to 2.1$)$ \\
\hline $\begin{array}{l}\text { Adjusted model } \\
\text { for employment }\end{array}$ & Mean $(95 \% \mathrm{Cl})$ & Mean (95\% Cl) & $\begin{array}{l}\text { Mean difference t0 } \\
\text { to t3 }(95 \% \mathrm{Cl})\end{array}$ & Mean (95\% Cl) & $\begin{array}{l}\text { Mean difference to } \\
\text { to t12 }(95 \% \mathrm{Cl})\end{array}$ \\
\hline \multirow[t]{2}{*}{ Retired (ref.) ${ }^{\star \star}$} & 46.2 (45.8 to 46.7 ) & 34.8 (34.3 to 35.3 ) & 11.4 (11.0 to 11.8$)$ & 34.0 (33.5 to 34.5$)$ & 12.2 (11.7 to 12.7$)$ \\
\hline & $\begin{array}{l}\text { Mean difference } \\
(95 \% \mathrm{Cl})\end{array}$ & $\begin{array}{l}\text { Mean difference } \\
(95 \% \mathrm{Cl})\end{array}$ & $\begin{array}{l}\text { Difference in } \\
\text { change from to to t3 } \\
(95 \% \mathrm{Cl}) \text { in relation } \\
\text { to the ref. }\end{array}$ & $\begin{array}{l}\text { Mean difference } \\
(95 \% \mathrm{Cl})\end{array}$ & $\begin{array}{l}\text { Difference in } \\
\text { change from t0 } \\
\text { to } 112(95 \% \mathrm{Cl}) \text { in } \\
\text { relation to the ref. }\end{array}$ \\
\hline $\begin{array}{l}\text { Employed/ } \\
\text { student }\end{array}$ & $1.1(0.3$ to 1.9$)$ & $-1.1(-1.9$ to -0.2$)$ & $-2.2(-2.9$ to -1.5$)$ & $-0.2(-1.1$ to 0.7$)$ & $-1.3(-2.1$ to -0.5$)$ \\
\hline Unemployed & 3.7 (1.6 to 5.7$)$ & $2.1(-0.1$ to 4.3$)$ & $-1.6(-3.8$ to 0.7$)$ & 6.2 (3.5 to 8.9 ) & $2.6(-0.3$ to 5.4$)$ \\
\hline
\end{tabular}

The numbers in the rows for the reference groups (primary school/retired) are actual numbers, while the numbers in the other rows are differences between that group and the reference. Negative prefix correspond to lower pain intensity or greater change pain intensity, as compared with the reference.

Numbers included in the models for education, $n=22588$.

Numbers included in the models for employment, $n=22477$.

${ }^{*}$ Model for education adjusted for age and gender.

†Under 3 years after secondary school.

$\ddagger 3-4$ years after secondary school.

§At least 5 years after secondary school.

IModel for employment adjusted for age, gender, BMI, educational level, SF-12 MCS, number of comorbidities and prior surgery on index joint.

${ }^{* \star}$ Retired, including self-imposed early retirement.

††Early retirement due to low ability to work.

BMI, body mass index; SF-12 MCS, 12-Item Short Form Survey for mental component summary score; t0, baseline; t3, after 3 months; t12, after 12 months.

reference, except for one group. Patients with long-term education had significantly less improvement in pain immediately after treatment $(2.0 \mathrm{~mm}, 95 \%$ CI 0.8 to 3.1$)$ and at 12 months $(2.0 \mathrm{~mm}, 95 \%$ CI 0.6 to 3.4$)$ compared with the reference (table 2).

In the secondary analysis, compared with the retired patients (reference), the other employment groups had higher baseline pain (1.1-7.2 $\mathrm{mm}$ higher). There was an average improvement in pain intensity from baseline to immediately after treatment of $11.4 \mathrm{~mm}(95 \%$ CI 11.0 to 11.8 ) and by $12.2 \mathrm{~mm}$ (95\% CI 11.7 to 12.7$)$ at 12 months in the reference group (table 2). Across employment status, on average, all patients improved in pain intensity. The average improvement differed significantly by employment group compared with the reference, except for one group, the unemployed. Patients on sick leave 


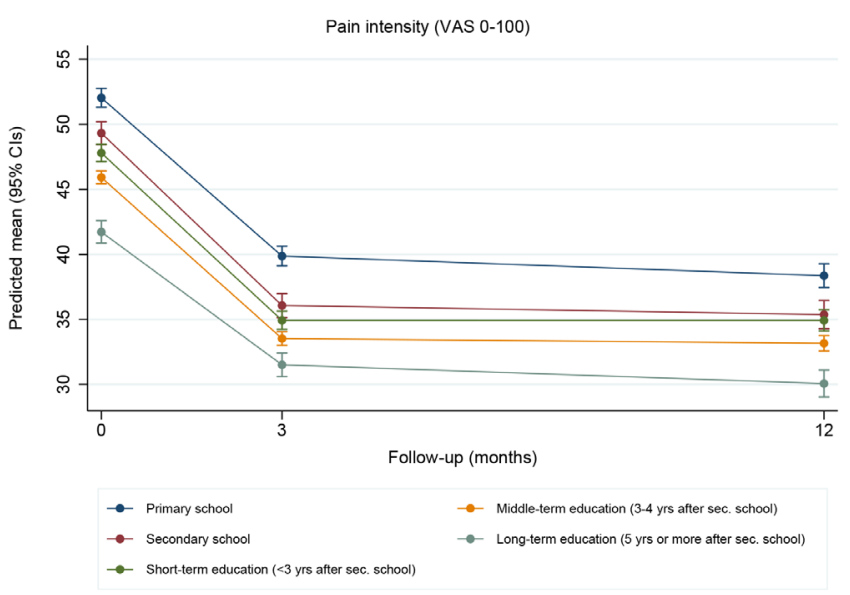

Figure 2 Educational level and pain intensity score (VAS 0-100) from baseline to 12-month follow-up. VAS, visual analogue scale.

had the greatest improvement in pain immediately after treatment $(-3.4,95 \% \mathrm{CI}-4.9$ to -1.9$)$ and at 12 months $(-4.5,95 \%$ CI -6.4 to -2.6$)$ compared with the reference (table 2).

The results of the joint-stratified analyses for the knee were similar to the combined analyses (online supplemental table 2). For the hip, there was only minor differences concerning the analysis with employment status, with less significant difference in change in pain at both follow-ups compared with the reference group (online supplemental table 3).

\section{DISCUSSION}

We found that improvements in pain after supervised exercise therapy and education in patients with knee and hip OA did not substantially differ by educational level or employment status (as measures of SES). Hence, lower SES was not associated with less improvement in selfreported pain at 3-month or 12-month follow-up.

Even though lower SES (eg, primary school only/on sick leave) was associated with greater improvement in pain, the absolute differences between groups were small and worse baseline pain intensity may have given potential for greater improvement compared with patients with lower baseline pain levels. Patients in our study with high SES (eg, long-term education or employed) both started and ended at an absolute lower pain intensity level compared with patients with lower SES. This finding is in line with previous studies. A recent US-based study found that patients with higher SES have lower pain and better function compared with lower SES patients prior to total knee replacement. ${ }^{4}$ The authors raise the question whether there are other factors specific to this group that contribute to differences in the timing of when they seek medical care/surgery. Similarly, a Swedish study reported that patients with higher education and income were generally younger at time of the first OA diagnosis.
This may suggest that patients with higher SES seek medical care at an earlier stage of the disease. ${ }^{7}$ Although some of the mean differences in pain relief between SES groups were statistically significant at both short-term and long-term follow-up, they were most likely not clinically significant, as the minimally clinically important change on a $0-100$ scale has been estimated to be 15 points $/ \mathrm{mm}$, based on change in patients with chronic musculoskeletal pain (including OA) ${ }^{15}$ Thus, our hypothesis of lower SES being associated with less improvement in self-reported pain was not supported. Although no clinically significant difference existed between groups, the absolute change in pain within SES groups were all just below the estimated cut-off. Thus, the beneficial effect on pain intensity across SES supports the use of exercise therapy and education as treatment of patients with knee and hip OA. It has been suggested that patients with lower educational attainment may require more support to self-manage or adhere to treatment. ${ }^{1}$ In our study, compliance to the exercise and patient education sessions did not considerably differ by level of education. Thus, the GLA:D programme seems to be feasible regardless of educational attainment.

We observed an inverse association between SES and baseline pain intensity comparable with previous studies. ${ }^{134}$ Furthermore, we observed that those with primary school only reported using pain medication more often $(67 \%)$ compared with patients with long-term education $(55 \%)$. Higher frequency of knee pain was related to lower individual SES (educational attainment and occupation) in a random sample of 7402 individuals from a population-based cohort in Sweden. ${ }^{1}$ Similarly, worse knee pain and function were associated with lower individual and community SES (group poverty rate) in a cross-sectional study from the Johnston County Osteoarthritis Project of 782 individuals with radiographic knee OA. ${ }^{3}$ Similar results was reported among 316 patients undergoing total knee replacement, where patients with lower educational attainment had higher pain intensity preoperatively. ${ }^{4}$ The mechanisms behind the association between lower SES and higher pain intensity remain uncertain. Some lifestyle risk factors of pain, OA and worse health-related quality of life, such as obesity, smoking and anxiety and depression, are reported to be more prevalent among people with lower SES. ${ }^{1}$ Moreover, SES characteristics may influence behaviours regarding seeking and access to medical care, which may influence pain. ${ }^{3}$ Adding to this body of literature from populationbased samples of knee pain, we found similar impact of SES in both knee and hip OA patients treated in primary care.

There are some limitations to the study. First, exposures and outcome were self-reported that makes them prone to misclassification. However, any misclassification would most likely be non-differential due to the prospective design. In most cases, this would bias the effect towards the null, but with three or more levels of exposure or outcome, the direction of bias depends on the level to which persons gets misclassified. Furthermore, 
employment status is likely a less sensitive measure for SES, compared with educational level, as it does not assess the individual's economic status (ie, type of occupation, income or financial support). We assumed, for example, unemployed and sick leave to be associated with different economic status, which might not be correct. We acknowledge that the way we have categorised patients based on employment status might have influenced the results. Thus, this analysis was also considered secondary. SES is a broad and complex construct, and it would have been beneficial with a more robust proxy measure to comprehensively capture the economic status. However, such data (eg, income distribution or median household income at the patient or neighbourhood level) is not available in the GLA:D. Second, our data were registry based, that is, we had no control group in our study, hence we are not able to estimate the effect of the GLA:D treatment. Third, we excluded patients who were missing pain intensity at both follow-ups. From the eligible sample of patients (28257), $20 \%$ were missing outcome data at both follow-ups (as depicted in figure 1). This might have introduced selection bias. However, patients excluded were similar to the study sample regarding mean age, BMI, distribution of gender, use of pain medication, prior surgery and most affected joint, with the exception of slightly higher baseline pain. We acknowledge that even if baseline characteristics were similar between the two groups, this does not address bias from unmeasured confounding. Fourth, the educational attainment in our sample was somewhat higher than reported in the general Danish population (in the age group 60-69 years). We believe, however, that the large number of participants included in GLA:D across Denmark, and treatment of knee and hip OA by clinicians in primary care practice, strengthens the generalisability of the results. Last, we acknowledge that generalisability of the impact of SES, as here represented by education and employment status, may not translate directly to other countries with different social structures. Thus, validation in different populations with alternate proxies of SES would be necessary.

The findings from our study contradicted our predefined hypothesis that patients with lower SES would experience less pain relief after participating in the GLA:D programme. Thus, adapting the delivery and content of the supervised exercise therapy and education programme according to SES is not warranted.

In conclusion, we found that improvements in pain after supervised exercise therapy and education in patients with knee and hip OA did not substantially differ by educational level nor employment status. Based on the findings from our study, using SES classified by educational level and employment status, lower SES should not be a reason to expect inferior outcomes in patients receiving evidence-based treatment for knee and hip OA.

\section{Author affiliations}

${ }^{1}$ Institute of Clinical Medicine, Faculty of Medicine, University of Oslo, Oslo, Norway
${ }^{2}$ Department of Research, Innovation and Education, Division of Clinical Neuroscience, Oslo University Hospital, 0slo, Norway

${ }^{3}$ Research Unit for Musculoskeletal Function and Physiotherapy, Department of Sports Science and Clinical Biomechanics, University of Southern Denmark, Odense, Denmark

${ }^{4}$ Department of Physiotherapy and Occupational Therapy, Næstved-SlagelseRingsted Hospitals, Region Zealand, Denmark

\section{Twitter Ewa Roos @ewa_roos and Søren Thorgaard Skou @STSkou}

Acknowledgements The authors would like to acknowledge all patients and clinicians reporting data to Good Life with osteoArthritis in Denmark (GLA:D) registry and others involved in GLA:D.

Contributors Study conception and design: MBJ, ER, DTG and STS. Recruitment of patients: STS and ER. Collection and assembly of data: STS, ER and DTG. Analysis and interpretation of the data: all authors. Drafting of the article or critical revision of the article for important intellectual content: all authors. Final approval of the article: all authors. All authors had access to the data and statistical reports in the study and take responsibility for the integrity of the data and the accuracy of the data analysis.

Funding The initiation of GLA:D was partly funded by the Danish Physiotherapy Association's fund for research, education and practice development; the Danish Rheumatism Association; and the Physiotherapy Practice Foundation. STS is currently funded by a grant from Region Zealand and a grant from the European Research Council (ERC) under the European Union's Horizon 2020 research and innovation programme (grant agreement No 801790). MBJ is funded by The Research Council of Norway (grant number 248817).

Disclaimer The funders had no involvement in any aspect of this manuscript.

Competing interests ER is deputy editor of Osteoarthritis and Cartilage, the developer of the Knee injury and Osteoarthritis Outcome Score (KOOS) and several other freely available patient-reported outcome measures and cofounder of Good Life with Osteoarthritis in Denmark (GLA:D), a not-for-profit initiative hosted at University of Southern Denmark aimed at implementing clinical guidelines for osteoarthritis in clinical practice. STS is associate editor of the Journal of Orthopaedic \& Sports Physical Therapy, has received grants from The Lundbeck Foundation, personal fees from Munksgaard, all of which are outside the submitted work. He is cofounder of GLA:D.

\section{Patient consent for publication Not required.}

Ethics approval The local ethics committee of the North Denmark Region waived the need for an ethical approval of GLA:D. The GLA:D registry has been approved by the Danish Data Protection Agency and all patients included have consented to submitting their data to the GLA:D registry, including that the data could be used for research purposes.

Provenance and peer review Not commissioned; externally peer reviewed.

Data availability statement Data are available on reasonable request. Deidentified data used in this study are available from ER (eroos@health.sdu.dk) and STS (stskou@health.sdu.dk) on reasonable request. Data cannot be reused unless a collaboration agreement has been signed by both parties.

Supplemental material This content has been supplied by the author(s). It has not been vetted by BMJ Publishing Group Limited (BMJ) and may not have been peer-reviewed. Any opinions or recommendations discussed are solely those of the author(s) and are not endorsed by BMJ. BMJ disclaims all liability and responsibility arising from any reliance placed on the content. Where the content includes any translated material, BMJ does not warrant the accuracy and reliability of the translations (including but not limited to local regulations, clinical guidelines, terminology, drug names and drug dosages), and is not responsible for any error and/or omissions arising from translation and adaptation or otherwise.

Open access This is an open access article distributed in accordance with the Creative Commons Attribution Non Commercial (CC BY-NC 4.0) license, which permits others to distribute, remix, adapt, build upon this work non-commercially, and license their derivative works on different terms, provided the original work is properly cited, appropriate credit is given, any changes made indicated, and the use is non-commercial. See: http://creativecommons.org/licenses/by-nc/4.0/.

\section{ORCID iDs}

Marianne Bakke Johnsen http://orcid.org/0000-0003-4300-5250

Ewa Roos http://orcid.org/0000-0001-5425-2199

Dorte Thalund Grønne http://orcid.org/0000-0002-8235-1175 
Søren Thorgaard Skou http://orcid.org/0000-0003-4336-7059

\section{REFERENCES}

1 Kiadaliri AA, Gerhardsson de Verdier M, Turkiewicz A, et al. Socioeconomic inequalities in knee pain, knee osteoarthritis, and health-related quality of life: a population-based cohort study in southern Sweden. Scand J Rheumatol 2017;46:143-51.

2 Busija L, Hollingsworth B, Buchbinder R, et al. Role of age, sex, and obesity in the higher prevalence of arthritis among lower socioeconomic groups: a population-based survey. Arthritis Rheum 2007:57:553-61.

3 Cleveland RJ, Luong M-LN, Knight JB, et al. Independent associations of socioeconomic factors with disability and pain in adults with knee osteoarthritis. BMC Musculoskelet Disord 2013;14:297.

4 Feldman CH, Dong Y, Katz JN, et al. Association between socioeconomic status and pain, function and pain catastrophizing at presentation for total knee arthroplasty. BMC Musculoskelet Disord 2015;16:18.

5 Guillemin F, Carruthers E, Li LC. Determinants of MSK health and disability-social determinants of inequities in MSK health. Best Pract Res Clin Rheumatol 2014;28:411-33.

6 Rahman MM, Kopec JA, Sayre EC, et al. Effect of sociodemographic factors on surgical consultations and hip or knee replacements among patients with osteoarthritis in British Columbia, Canada. $J$ Rheumatol 2011;38:503-9.

7 Wetterholm M, Turkiewicz A, Stigmar K, et al. The rate of joint replacement in osteoarthritis depends on the patient's socioeconomic status. Acta Orthop 2016;87:245-51.

8 Brennan SL, Lane SE, Lorimer M, et al. Associations between socioeconomic status and primary total knee joint replacements performed for osteoarthritis across Australia 2003-10: data from the Australian orthopaedic association national joint replacement registry. BMC Musculoskelet Disord 2014;15:356.

9 Bannuru RR, Osani MC, Vaysbrot EE, et al. OARSI guidelines for the non-surgical management of knee, hip, and polyarticular osteoarthritis. Osteoarthritis Cartilage 2019;27:1578-89.

10 Skou ST, Roos EM. Good life with osteoArthritis in Denmark (GLA:D ${ }^{\mathrm{TM}}$ ): evidence-based education and supervised neuromuscular exercise delivered by certified physiotherapists nationwide. BMC Musculoskelet Disord 2017;18:72.

11 Ageberg E, Link A, Roos EM. Feasibility of neuromuscular training in patients with severe hip or knee OA: the individualized goalbased NEMEX-TJR training program. BMC Musculoskelet Disord 2010;11:126.

12 Sandal LF, Roos EM, Bøgesvang SJ, et al. Pain trajectory and exercise-induced pain flares during 8 weeks of neuromuscular exercise in individuals with knee and hip pain. Osteoarthritis Cartilage 2016;24:589-92.

13 Villadsen A, Overgaard S, Holsgaard-Larsen A, et al. Immediate efficacy of neuromuscular exercise in patients with severe osteoarthritis of the hip or knee: a secondary analysis from a randomized controlled trial. J Rheumatol 2014;41:1385-94.

14 von Elm E, Altman DG, Egger M, et al. The strengthening the reporting of observational studies in epidemiology (STROBE) statement: guidelines for reporting observational studies. Lancet 2007;370:1453-7.

15 Salaffi F, Stancati A, Silvestri CA, et al. Minimal clinically important changes in chronic musculoskeletal pain intensity measured on a numerical rating scale. Eur J Pain 2004;8:283-91.

16 Shimonovich M, Pearce A, Thomson H. Assessing causality in epidemiology: revisiting Bradford Hill to incorporate developments in causal thinking. Eur J Epidemiol 2020 doi:10.1007/s10654-02000703-7 